\title{
A Cycle Path for the Safeguard of Cultural Heritage: Augmented Reality and New LiDAR Technologies
}

\author{
Maurizio Perticarini \\ Valeria Marzocchella \\ Giovanni Mataloni
}

Abstract

The development of applications for mobile devices that exploit the potential of GIS and augmented reality, turns out to be one of the best solutions to encourage sustainable tourism, slow mobility and the enhancement of the cultural heritage present in a given territory. The GIS map of the Abruzzo stretch of the Ciclovia degli Appennini identifies and connects some important artefacts which, by means of Laser Scanning surveys, are the object of the research study. The analysed case of Santa Maria ad Cryptas in Fossa (AQ), one of the medieval churches along the greenway, has provided new ideas for the use of this type of technology. The careful analysis of the architecture and the paintings inside, has favoured the use of augmented reality to bring out elements that are no longer visible (pointed arched roof) and has established connections with other pictorial representations of the period. Lastly, the experiment performed with the new Lidar sensor supplied with the iPhone 12 Pro Max device leads to two considerations: the technology of current smartphones is becoming more and more accurate and reliable; the mixed system of Laser Scanning and photogrammetry, integrated into mobile devices, could guarantee excellent stability in the use of augmented reality.

Keywords

greenways, slow mobility, augmented reality, laser scanning, LiDAR.

Santa Maria Ad Cryptas, Fossa (AQ)

Longitudinal section of the point cloud.

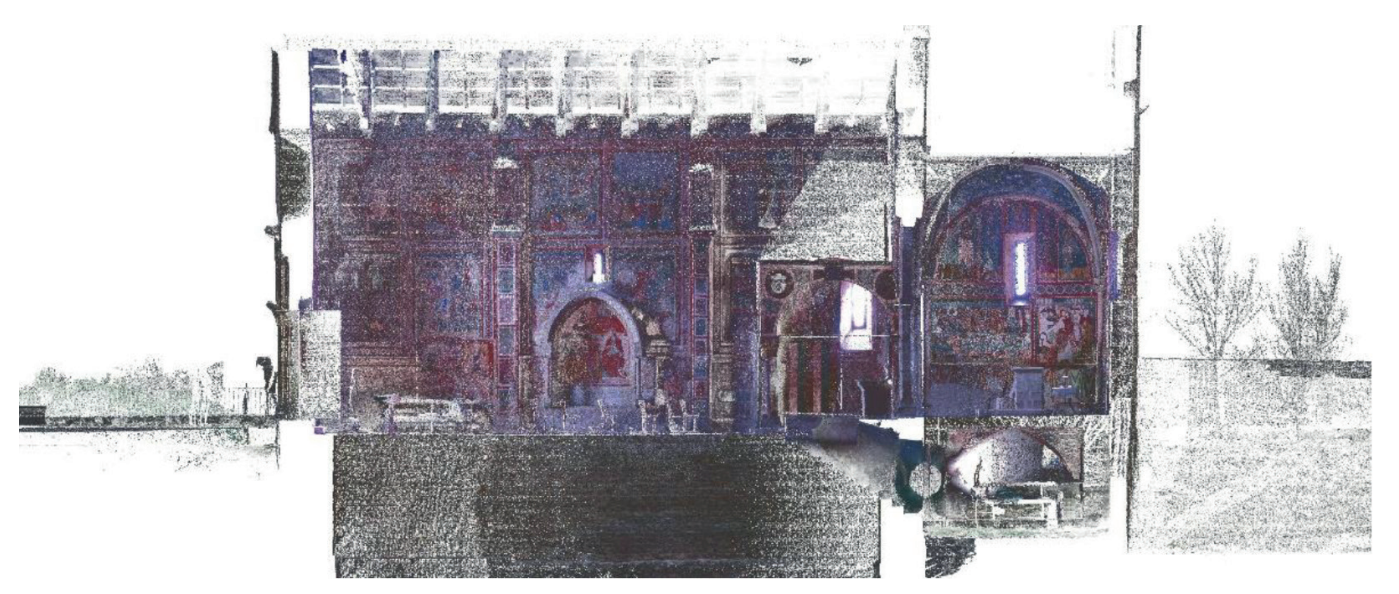




\section{Introduction}

In recent years there has been increasing attention to safeguard policies of the territory and cultural heritage.The theme of sustainable tourism and the so-called Green Economy has acquired even more importance due to the recent COVID 19 pandemic which has had a considerable impact on the global economy and especially on small regional realities [Cazzani, Boriani 202I]. The research project aims to identify a historical -landscape- architectural itinerary in the Abruzzo region, which constitutes a real path of knowledge (Know-path) [Zhou et al. 20 I5]; census the historical and cultural assets that are encountered along the route and create an application for mobile devices that allows GPS navigation to reach the hotspots and helps users to discover the artefacts present in the area through the use of new technologies such as virtual or augmented reality [Shih, Diao, Chen 2019; Ye, Qiu 2021]. Necessary for the project is a 'green' infrastructure that favours slow tourism and constitutes a seam for an area with a strong settlement dispersion, but with great tourist potential. The route also reconstructs the history of the surrounding landscape, both anthropic and natural: for a few kilometres it follows the course of the Aterno river [Ghisetti 20 I7] and continues along the ancient path of the tratturo that was used by shepherds for transhumance. The research takes as its main reference the Abruzzo stretch which is part of the much longer Ciclovia degli Apennini. Today it is only a path marked in GPS, but it runs through all the Apennines starting from Colle di Cadibona (Liguria) up to Madonie (Sicilia). A route approximately $1600 \mathrm{~km}$ long that crosses Liguria, Emilia-Romagna, Tuscany, Umbria, Lazio, Marche, Abruzzo, Molise, Basilicata, Calabra and Sicilia. (M.P.).

\section{Identification of the route and points of historical, cultural and landscape interest}

Using the Qgis software, the route of the Ciclovia degli Apennini and the various historical, cultural and landscape hotspots were inserted into an application for mobile devices (fig. I). The Abruzzo section of the greenway is partly accessible by bike because it is built on cycle paths and on quiet streets. It starts from the northern border of the region, in Poggio Cancelli (AQ), a village in the middle of the Gran Sasso and Monti della Laga National Park on the shore of the Lago di Campotosto. The journey continues along the lake and then pass the Valico delle Capannelle, used in the past by shepherds during the transhumance who moved from the Abruzzo mountains to the Roman countryside. After a panoramic descent, the route crosses L'Aquila, the capital of Abruzzo, where there are the most important medieval, renaissance, baroque and neoclassical architectures of the region. The Basilica of Santa Maria di Collemaggio is the greatest expression of the architecture of Abruzzo, was founded in 1288 by Pietro da Morrone (Celestino V) and has multiple construction phases due to the frequent earthquakes that have struck the region over the centuries. The research identifies the specific case as an important hotspot of the cultural path: augmented reality is the best representation tool to bring the Basilica back to its baroque phase, now no longer visible following subsequent transformations (fig. 2). The same process can also be used for the Fontana delle 99 cannelle, which has various construction phases. From this point on, the cycle path follows the section of the railway that descends from L'Aquila to the city of Sulmona (AQ) [Rovelli et al. 2020]. The railway provides great support to the user who, at any time, can leave the cycle path to reach the place of arrival more quickly with the help of the train. The green way continues passing through the village of Fossa (AQ) where there are artefacts of both landscape and cultural value: the ruins of the walls, with a circular tower nearby, hide a necropolis of 570 tombs; then there is the ancient mill with a ruined structure in front of it that most likely had the function of a rest station for travellers and the Church of Santa Maria ad Cryptas, an artifact taken as a case study of the research. The route then passes through the Sirente Velino regional natural park until reaching Fontecchio (AQ) where there is the Fontana Civica -very similar in composition to the Fontana Maggiore in Perugia- which is another point of historical interest reported by the App. Going further down, the route intercepts the fortified village of Beffi (AQ) which stands in the middle of the Aterno valley [Ghisetti 2017] and allows a view of Monte Sirente. From the village it is possible to reach the church of San Michele, the medieval 
Fig. I. Interactive GIS map. Maurizio Perticarini.

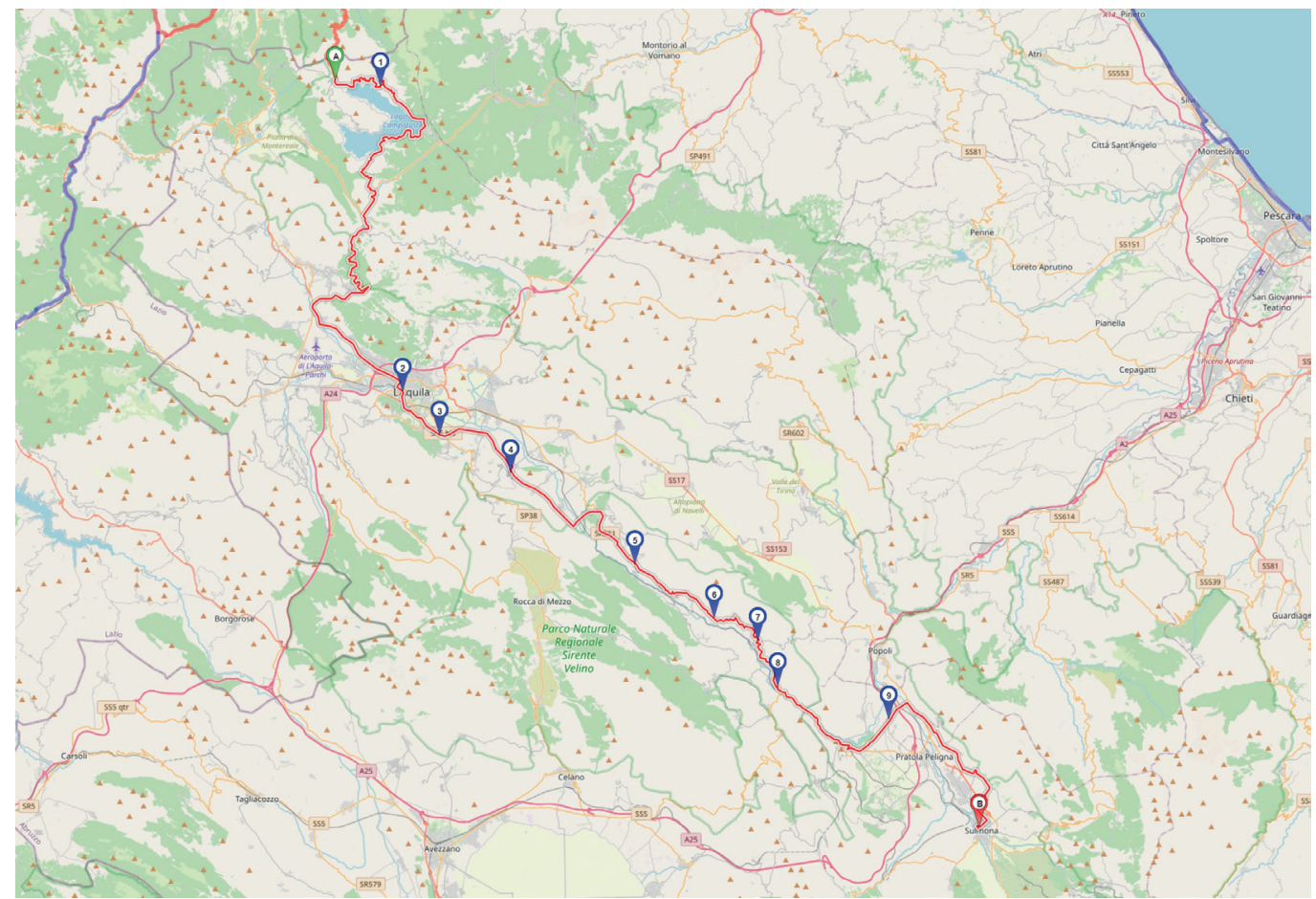

watchtower and it is easy to see the nearby tower of Goriano Valli on the opposite side of the valley. Next are the villages of Acciano, Molina Aterno and the Gole di San Venanzio (AQ) where the Hermitage complex is located. It consists of a thirteenth-century church dedicated to San Venanzio di Camerino, a loggia suspended over the river built in the sixteenth century and, further down towards the riverbed, an area carved into the rock, a space inhabited by the saint. The cycle route passes through Corfinio (AQ), the ancient capital of the Lega Italica, following the path of Via Tiburtina Valeria and creating a visual telescope on the remains of the Roman Murgini (2nd century funeral monuments made up of stone pebbles) (fig. 3).These are interesting artefacts for the application of augmented reality to provide hypotheses on their original shape and volume. The last stop on the route is Sulmona (AQ), a city rich in artifacts of historical and cultural interest including the medieval aqueduct, the Church of Santa Maria della Tomba and the Complesso della Santissima Annunziata.The latter constitutes an interesting opportunity for the use of augmented reality for its four construction phases ranging from 1320, the year in which the works began, up to the restoration of I706. (M.P.).
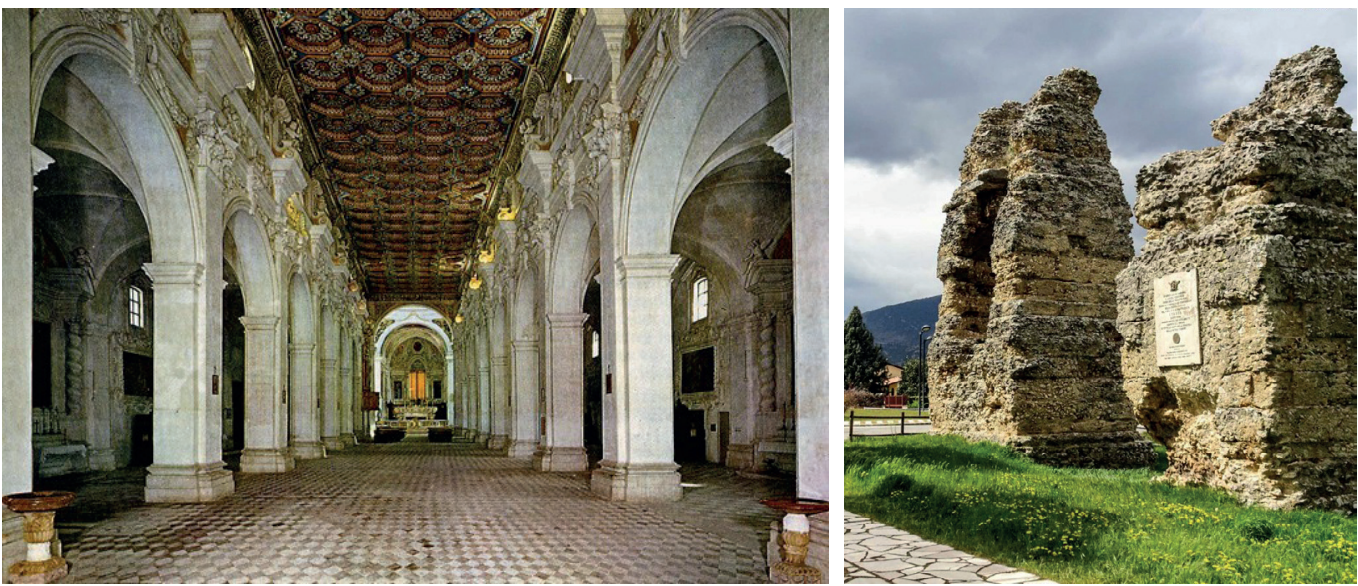

Fig. 2. Baroque phase of the Basilica of Collemaggio. The Baroque was removed by the Superintendent Mario

Fig. 3. Murgini, Corfinio (AQ) 
Fig. 4. Santa Maria ad Cryptas, Fossa (AQ).

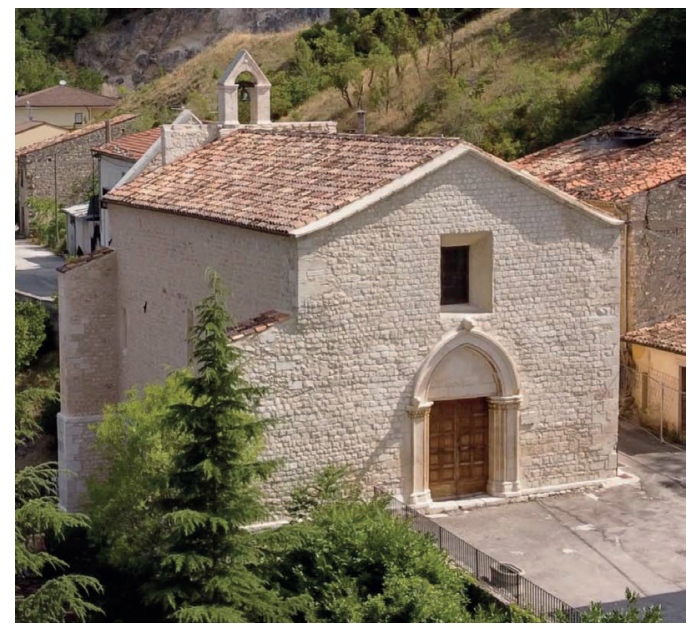

The case study: Santa Maria ad Cryptas di Fossa

The church of Santa Maria ad Cryptas (fig. 4) takes its name from some nearby caves. It is located in Fossa (AQ) within the Valle Subequana, at the foot of Monte d'Ocre. It was built in the second half of 1200 by the Cistercian monks. The facade consists of a large portal with an ogival archivolt built in 1300 and a recently built rectangular window. As in San Pellegrino a Bominaco - which was also built by the Cistercians- it should have had a pointed barrel vault as a roof. This can be seen from the spandrels that emerge from the side walls of the nave. The small altar at the bottom left is the only one dating back to the period of construction of the church and is located below a late-seventeenth-century aedicule. At the end of the single nave there is a pointed triumphal arch and below it, there is a small staircase that leads to a square-shaped crypt containing a small stone altar composed of a support slab and a column trunk. The church is entirely covered with frescoes: on the right side and on the main arch they are Benedictine and date back to the late thirteenth century, on the left side they date back to the thirteenth century and are from the Sienese School. On the inner wall of the façade the Last Judgment is painted on four horizontal strips, it dates to 1283 and is a work performed by local painters. (M.P.).

\section{Graphic composition at the service of new technologies: compared works}

The research wanted to use augmented reality also to the paintings inside the church which were studied from a graphic and formal point of view. By framing with the camera, the AR app provides information on the content of the work and the comparison with other similar works do not present on the site. The language and geometry of the images were analyzed, identifying the lines of force to offer support for reading the authors' idea, and for the correct reconstruction of vector images in AR. The work examined is L'Annunciazione of Antonio di Paolo di Fossa and Sebastiano di Cola da Casentino (fig. 5), both minor authors who recall the great Renaissance of Tuscany, Piermatteo d'Amelia (apprentice of Filippo Lippi) but partly also Botticelli. As in Botticelli's works, the painting becomes heavy in the folds of the clothes while maintaining the elegance in the living faces of the characters depicted. The scene is inscribed in a Godica aedicule and close to the pointed arch there are four figures: S. Sebastiano and his elegant presence conferred by his golden curls, S. Bernardino who recalls the Ferrarese and Marchiggiana painting, a Saint Knight not easily identified and Saint Caterina D'Alessandria. The scene exploits the frame of the newsstand creating an optical cone towards a portico and a courtyard. On her right there is the Virgin seated on a marble throne with a lectern in front of her; she has a graceful and elegant face, her left hand is stretched forward towards the lectern, about to welcome the angel lily, who is ready to 
Fig. 5. Cappella dell'Annunciazione of Sebastiano di Cola da Casentino e Antonio di Paola di Fossa (AQ), I 486. Image token from Atlante by Francesco Cardarelli.

Fig. 6. Annunciazione, Piero della Francesca, 1452-

|458.
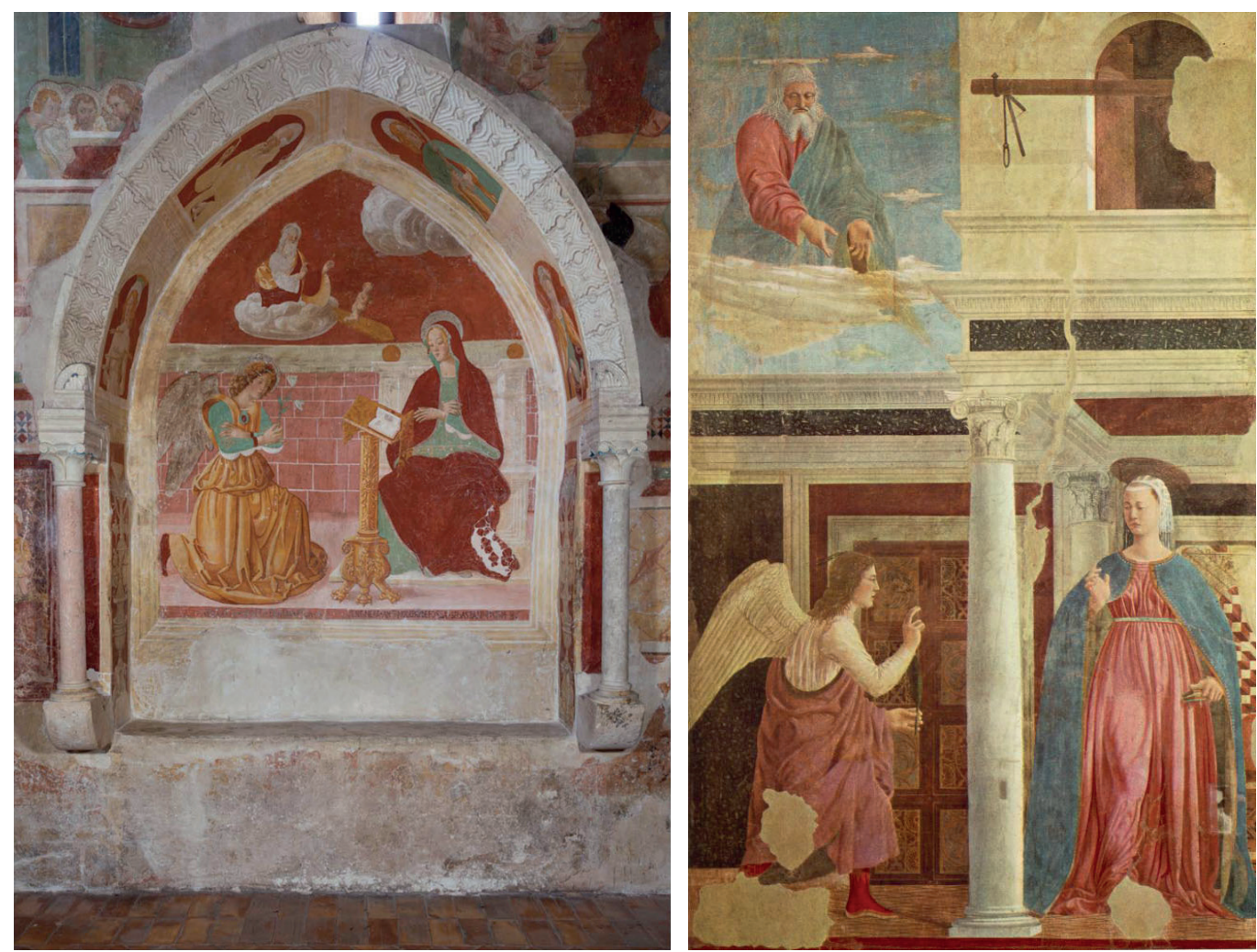

tell her about her motherhood. The two figures are well proportioned, and the anatomical details are reproduced with precision. Among the main elements that contribute to giving greater realism to the scene is the play of light and shadow, which gives depth to the figures. The face of the Virgin, as well as the angel's dress, are well defined and elegant and thanks to the light they are transformed into sculptures. The chiaroscuro and shadows give the figures a great plastic strength. Above, beyond the brick wall, a red sky is the background, and a cloud welcomes the blessing of God the Father. From the cloud comes a ray of golden light on which the baby Jesus is. The message is transformed into an image. The analysed work recalls the perspective; the architectures and characters are arranged in a measurable space that starts from the perspective floor at the base of the throne on which the virgin is seated and from the step that precedes the scene. This is divided into two parts by the lectern in the centre. The lines of force start from the base of the Virgin's throne and flow into the vanishing point placed in the centre of her joined hands; other lines of force start from the back joining in the same point. Another line of force, starts from God the Father, crosses the beam of light and ends in the face of the Virgin creating a bond. The perspective is also captured by the painted frame, which reinforces the depth of the pointed aedicule: the lines of force break through the two-dimensional image and start from the base of the two columns that support the arch of the aedicule, pass through the inclination of the lectern and converge at the centre of the scene underlining its meaning.

The comparison:

In the case analysed, the architectural space alludes to an imaginary space reinforced by the newsstand. This differs from the Annunciation by Piero della Francesca (fig. 6), where the position of the (painted) columns vertically separates the scene into two halves, as occurs in other Renaissance representations: on the one hand there is a legacy of the traditional compartments of the polyptychs, the other symbolizes the contact between the divine and the human world. The diagonal of the architrave, which continues in the profile of the projecting cornice, joins the hands of God the Father with the face of Maria and suggests the progress of the Holy Spirit. The perspective is therefore, in this case, placed at the service of the Christian theme. (V.M.). 


\section{The Laser Scanning survey}

In support of the preliminary investigation, an excerpt of the CTR of the Abruzzo Region was consulted, due to the conformation of the land which, at the point where the church stands, presents a considerable difference in height. The survey was carried out with the Laser Scanning technique [Carraro et al. 2019] by means of the BLK 360 from LEICA GEOSYSTEM, a cutting-edge system equipped with a camera and thermal imager calibrated to support the laser.The camera gives the point cloud a high level of realism and the thermal imaging camera facilitates thermal mapping [Mataloni 2021, pp. I55-159].

\begin{tabular}{|c|c|}
\hline Imaging scanner & $\begin{array}{l}\text { 3D scanner with integrated spherical imaging system } \\
\text { and thermographic sensor with panorama function }\end{array}$ \\
\hline \multicolumn{2}{|l|}{ Technical specifications } \\
\hline Dimensions & Height: I 65mm / Diameter: I00mm \\
\hline Weight & $\mathrm{I} \mathrm{Kg}$ \\
\hline \multicolumn{2}{|l|}{ Start-up, Communication } \\
\hline Stand Alone Start-up & Single Button Start \\
\hline Remote Start & App for iPad, Apple iPad Proß I2.9"' iOS I0 or later \\
\hline Wireless Communication & Integrate Wi-Fi $(802.1 \mathrm{l} \mathrm{b/g/n)}$ \\
\hline \multicolumn{2}{|l|}{ Laser Scanning } \\
\hline Measurement System & High speed system with WFD technology \\
\hline FOV Acquisition Angle & $360^{\circ}$ Horizontal $/ 300^{\circ}$ Vertical \\
\hline Range & From 0.6 to 60 meters \\
\hline Acquisition frequency & 360000 points per second \\
\hline Precision & $4 \mathrm{~mm}$ to $10 \mathrm{~m} / 7 \mathrm{~mm}$ to $20 \mathrm{~m}$ \\
\hline Method of Acquisition & 3 user-selectable modes \\
\hline \multicolumn{2}{|c|}{$\begin{array}{l}\text { Acquisition of RGB and Ther- } \\
\text { mographic images }\end{array}$} \\
\hline RGB Camera System & $\begin{array}{l}3 \text { I5Mpixel cameras, maximum resolution I50Mpx } \\
\text { HDR, LED Flash, } 360^{\circ} \times 300^{\circ} \text { coverage }\end{array}$ \\
\hline Thermographic Camera & $\begin{array}{l}\text { Flir longwave thermographic camera with } 360^{\circ} \times 70 \\
{ }^{\circ} \text { coverage }\end{array}$ \\
\hline \multicolumn{2}{|l|}{ Performance } \\
\hline Acquisition speed & $\begin{array}{l}\text { In less than } 3 \text { minutes it acquires the point cloud, the } \\
\text { spherical image and the thermal image }\end{array}$ \\
\hline
\end{tabular}

Despite the difference in height between the upstream and downstream parts of the building, the acquisitions were carried out at an average distance of 5 meters from the facades and $7 / 8$ meters from each other. A total of 43 scans of 357,206,736 points were performed with an average overlap of $45 \%$ and an overall group error of less than $6 \mathrm{~mm}$ (fig. 7). 12 scans were performed inside, 31 outside and 3 of the latter inside the crypt. The smooth geometries of the exterior and interior made flat or spherical targets unnecessary along the scan path and the sensor was placed on a telescopic tripod at a height of 3 meters for greater accuracy in capturing details higher up. All data was managed by specific Leica software: the Register 360 for recording the scans and, once the 3D model was obtained, the Leica Cloudworks for Autocad to perform the explorations of the 3D model and the cross-sections (fig. 8). The three-dimensional point model provided both the metric-quantitative data, the reflectance, the radiometric data and the thermographic data (fig. 9). (G.M.). 
Fig. 7. External Laser Scanning survey. Giovanni Mataloni

Fig. 8. Cross-section of the point cloud. Giovanni Mataloni.
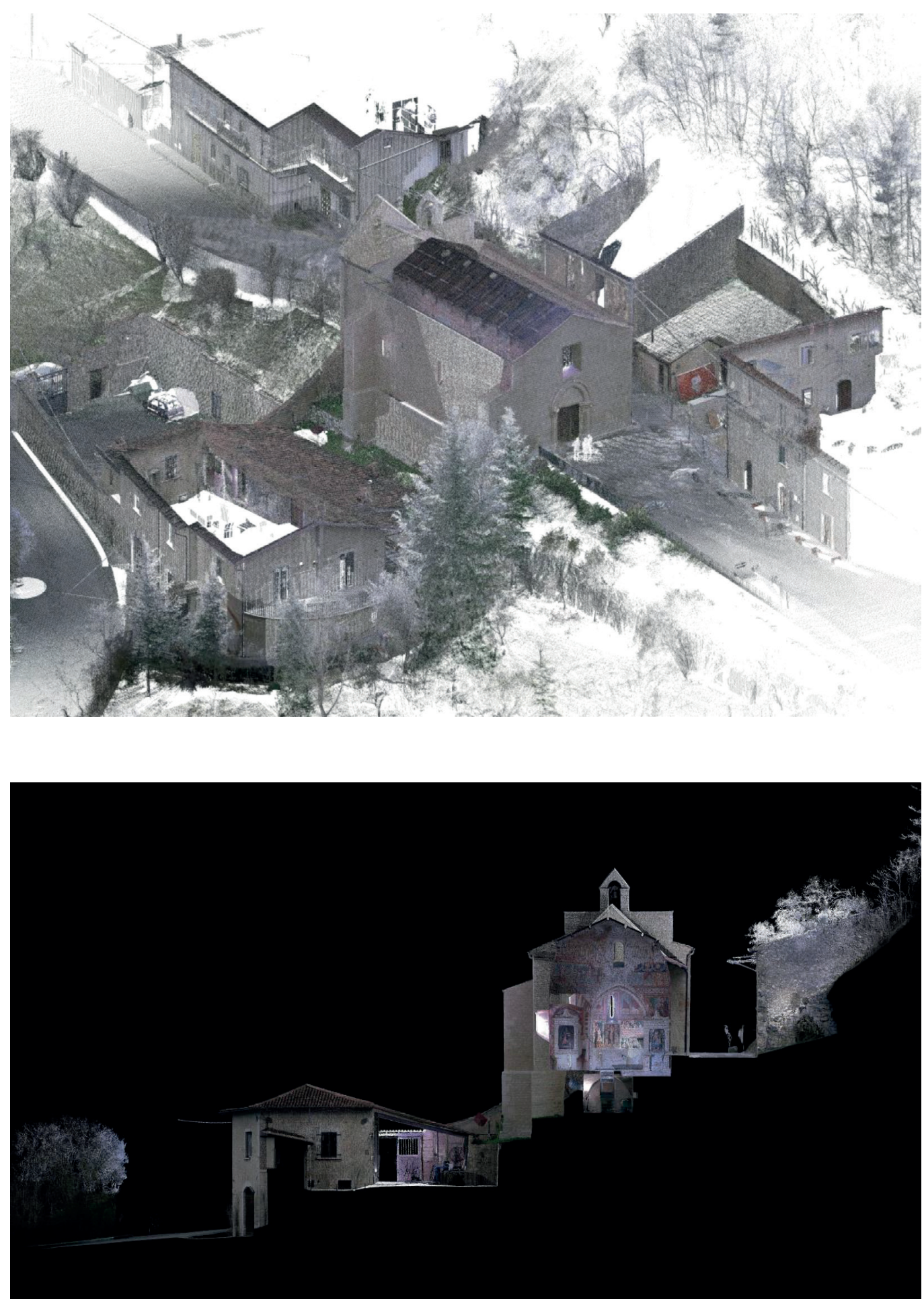

Survey tests using the IPhone 12 Pro Max LiDAR system and hypothesis of use for augmented reality

On the same case study, some surveys were carried out with the aid of the LiDAR system integrated in the new iPhone 12 Pro Max [Yao 2020] which, although today it is not within everyone's reach, will most likely become a reliable system as regards the use of augmented reality. In particular, the central altar and the smaller one inside the late seventeenth-century 


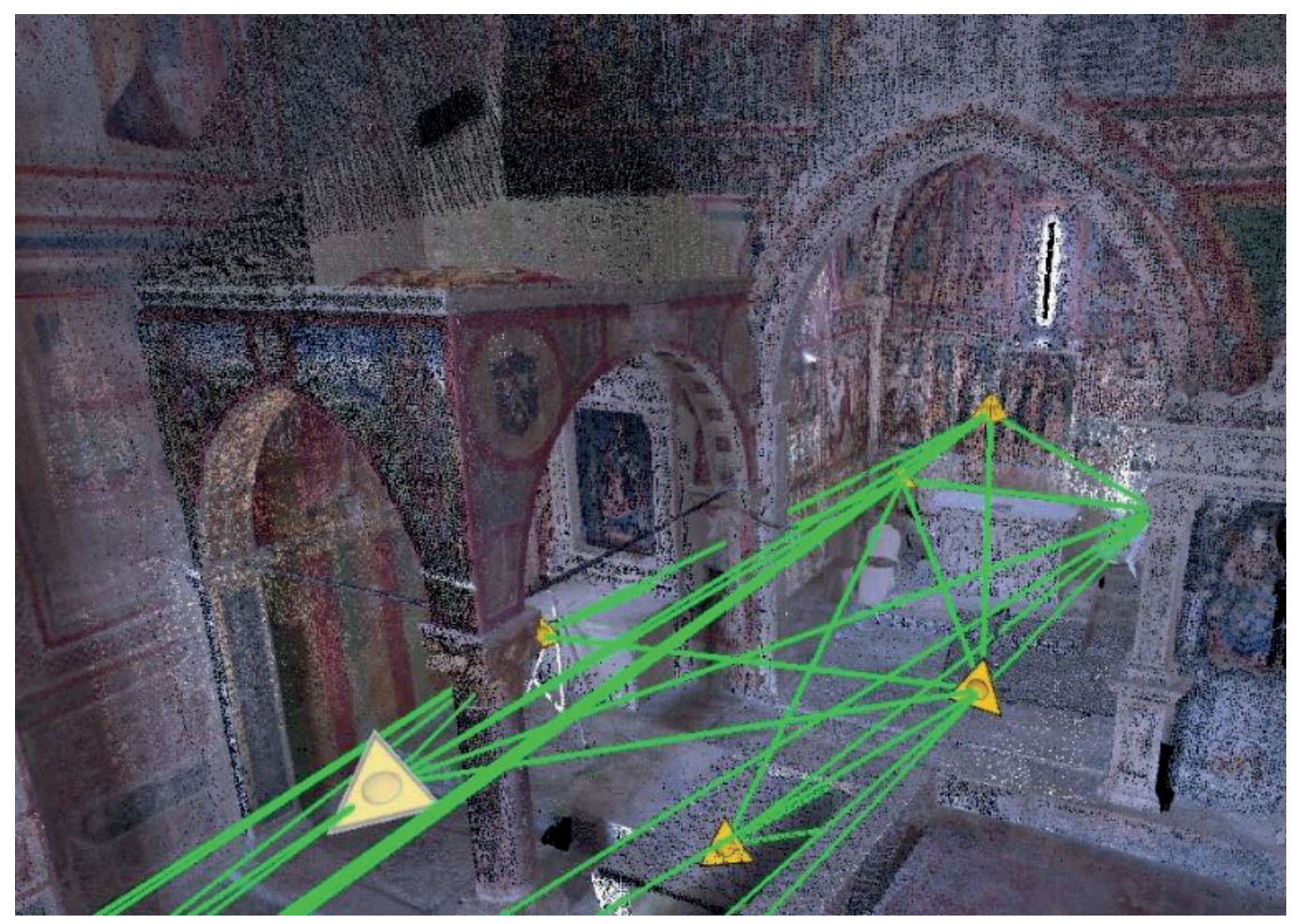

aedicule were surveyed. Small portions of the interior of the church were chosen because the system has the limit of a maximum range of 5 meters, so it is not yet suitable for larger reliefs. However, the accuracy of the point clouds seems to be quite high, considering it is a portable system and costs far more affordable than professional devices. In addition, the Polycam App used by the smartphone allows for export to various formats, including the most common ones used for meshes. The hybrid system of laser scanner and photogrammetry guarantees a realistic rendering of the detected objects and could be a good way to carry out rapid surveys and preliminary investigations. The most important application of this system lies in the subsequent development of the Augmented Reality App: the specific case of the church of Santa Maria ad Cryptas, as already mentioned, presents spandrels that suggest the barrel-vaulted shape of the original roof; thanks to the help of augmented reality and the lidar system, the vaulted cover appears stable inside the mobile device. The system, without the need for markers or GPS coordinates, can scan the surrounding surfaces and volumes in real time and use that has a spatial reference to superimpose even large virtual objects. (M.P.).

\section{Conclusions}

The study of alternative and eco-sustainable routes makes an area of such great tourist and economic potential more accessible. In the case studied, the Aterno river acts as a common thread by establishing a physical connection between the places examined. Augmented reality and the technologies used for the surveys are tools that allow to establish virtual connections between the artifacts, to compare the historical phases and the formal aspects that compose them. The case of Santa Maria ad Cryptas contains all research approaches: augmented reality -made stable by the Lidar device present on modern mobile devicesallows the correct display of the frescoes and the pointed barrel vault on the screen of the smartphone, adds historical and informative contents and guides the user in the comparison with works of similar cultural importance. 
Fig. 10. Survey of the main altar by means of the Polycam App and the LiDAR system of the iPhone 12 Pro Max Maurizio Perticarini.

Fig. II. Survey of the aedicule using the Polycam App and the iPhone 12 LiDAR system. Maurizio Perticarini.
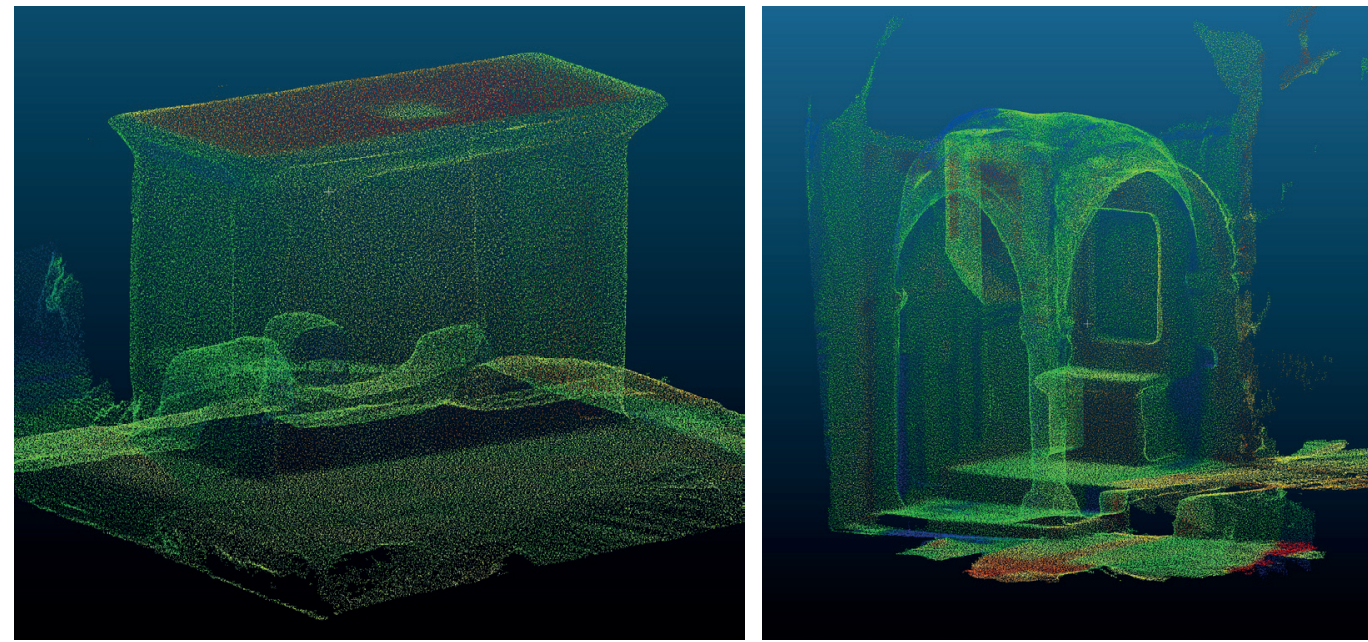

\section{References}

Carraro F. et al. (2019). The 3d survey of the Roman Bridge of San Lorenzo In Padova (Italy): a comparison between SFM and TLS methodologies applied to the arch structure. In International Archives of the Photogrammetry, Remote Sensing and Spatial Information Sciences - ISPRS Archives, 42(2N I 5), pp. 255-262.

Cazzani A., Boriani M. (202I). The role of historic roads to preserve and valorize the landscape. In Research for Development, pp. 85-103.

Ghisetti A. (2017). L’Aterno Pescara: Mistero di un fiume. L'Aquila:Textus Edizioni.

Mataloni G. (202 I). Applicazioni geometriche nella modellazione 3d della chiesa di Santa Maria ad Cryptas. In M. Maccherini L. Pezzuto (a cura di). Santa Maria ad Cryptas. Storia, arte, restauri, pp. I55- I59. Napoli: Editori Paparo.

Rovelli R. et al. (2020). From railways to greenways: a complex index for supporting policymaking and planning. A case study in Piedmont (Italy). In Land Use Policy, 99 (June), p. 104835.

Shih N. .., Diao P. H., Chen Y. (2019). ARTS, an AR tourism system, for the integration of 3D scanning and smartphone AR in cultural heritage tourism and pedagogy. In Sensors (Switzerland), 19(17).

Yao Z. (2020). VTQuestAR : An Augmented Reality Mobile Software Application for Virginia Tech Campus Visitors Zhennan Yao VTQuestAR : An Augmented Reality Mobile Software Application for Virginia Tech Campus Visitors'. Master Thesis, pp. I-65.

Ye Y., Qiu H. (202I). Exploring Affecting Factors of Park Use Based on Multisource Big Data: Case Study in Wuhan, China. In Journal of Urban Planning and Development, I 47(I), p. 05020037.

Zhou P. et al. (20I5). Study of greenway site selection based on cultural route: Research on Grassland silk road (from Xanadu to Zhongdu). In Green Building, Materials and Civil Engineering - Proceedings of the 4th International Conference on GreenBuilding, Materials and Civil Engineering, GBMCE 20 I4, pp. 84I-848.

\section{Authors}

Maurizio Perticarini, Università della Campania “Luigi Vanvitelli”, maurizio.perticarini@unicampania.it Valeria Marzocchella, Università della Campania “Luigi Vanvitelli”, valeria.marzocchella@unicampania.it Giovanni Mataloni, Università G. d'Annunzio Chieti Pescara, giovanni.mataloni@unich.it

To cite this chapter. Perticarini Maurizio, Marzocchella Valeria, Mataloni Giovanni (2021). A Cycle Path for the Safeguard of Cultural Heritage: Augmented Reality and New LiDAR Technologies. In Arena A., Arena M., Mediati D. Raffa P. (a cura di). Connettere. Un disegno per annodare e tessere Linguagoi Distanze Tecnologie. Atti del $42^{\circ}$ Convegno Internazionale dei Docenti delle Discipline della Rappresentazione/Connecting Drawing for weaving relationship. Langures Distances Technologies. Proceedings of the 42th Internationol Conference of Representation Disciplines Teachers. Milano: FrancoAngeli, pp. 257|-2579. 